\title{
Ways of avoiding intervention: Some thoughts on the development of object relatives, passive and control.
}

\author{
Adriana Belletti - Luigi Rizzi \\ University of Siena \\ www.ciscl.unisi.it
}

Children at the stage of language learning

which borders on adult competence can offer

valuable material for studying degrees of

complexity that may be otherwise difficult to detect.

C.Chomsky (1969; p.121)

\section{Introduction.}

In her The Acquisition of Syntax in Children from 5 to 10, Carol Chomsky observed that certain syntactic constructions such as subject control with promise type verbs are acquired surprisingly late. She argued that initially children strictly adhere to Rosenbaum's 1967 Minimal Distance Principle, barring subject control, and exceptions to the principle are acquired at later points in development. In this paper we would like to argue that these cases are part of a much larger class of syntactic configurations which are "complex" for the child to compute. We propose that the critical notion is "intervention": the child cannot compute a local relation across an intervener close enough in structural type to the target of the relation. In fact, this follows from a general locality principle, Relativized Minimality (RM, Rizzi 1990, 2004), also holding in adult grammars; our hypothesis is that the intervention effect can be voided through the adoption of certain structural strategies which become accessible only at later stages in development. We will first present two cases discussed in previous work, which involve different adult strategies avoiding intervention: object relatives and passive; we will then go back to control and try to trace back subject control to a similar explanatory scheme.

It is a well established fact that children till after age 5 are unable to properly comprehend and produce object relatives while subject relatives are understood and produced as soon as the relative construction is mastered around age 3. In joint work with Naama Friedmann (Friedmann, Belletti, Rizzi 2009), we have argued that the difficulty arises from the intervention of the subject in the chain connecting the head of the relative with the object gap:

(1) Show me:

The lion that the elephant wets <the lion>

We traced back this effect to RM.

\section{Some relevant background on $\mathrm{RM}$}

Theoretical studies have introduced RM as a locality principle capturing intervention effects. In a configuration like the following:

(2) $\quad \mathrm{X} \ldots \mathrm{Z} \ldots \mathrm{Y}$

a local relation between $\mathrm{X}$ and $\mathrm{Y}$ cannot hold if $\mathrm{Z}$ intervenes, and $\mathrm{Z}$ is a position of the same type as X. (Rizzi 1990, 2004). This principle has been expressed in slightly different forms under different 
names in various minimalist models (e.g. Minimal Link Condition, Minimal Search, Featural Relativized Minimality: see Chomsky 2000, 2001, 2008, Boeckx 2007, Starke 2001). The initial empirical motivation for the principle had to do with the unextractability of certain wh-elements from weak islands like indirect questions, as illustrated in (3):

(3) a How do you think [ John behaved __ ] ?

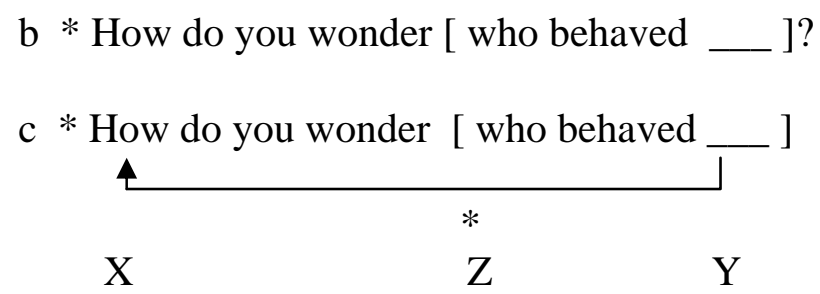

In representation (3)c the relation between how and its trace is disrupted by the intervention of who, an element belonging to the same featural type as how, a wh-operator.

The central idea of Friedmann, Belletti, Rizzi (2009) is that the same principle is implicated in the difficulty that children experience with object relatives. If it seems natural to relate all intervention effects to the same core principle, an immediate difficulty is represented by the fact that the intervention of the subject does not appear to affect the acceptability of object relatives in adults. A possible analytic path is offered by the observation that intervention effects are modulated by certain characteristics of the intervener $(\mathrm{Z})$ and the target $(\mathrm{X})$ of the relation. For instance, the unacceptability of sentences like (3)b decreases if the constituent moving to the target position is not a simple wh-word, but a complex wh-phrase containing a full lexical noun phrase, which we will refer to from now on as "lexical restriction". ${ }^{1}$ This is illustrated in (4):

(4) ? Which problem do you wonder how to solve < which problem>?

Straightforward evidence that presence vs absence of a lexical restriction plays a crucial role is offered by the paradigm of combien extraction in French illustrated in (5) a,b:

(5) a ? [Combien de problèmes] ne sait-il pas [ comment résoudre _ ]? 'How many of problems don’t you know how to solve?'

b * Combien ne sait-il pas [ comment résoudre [__ de problèmes ]? 'How many don't you know how to solve of problems?'

(6) a [Combien de problèmes] a-t-il résolus _ ? 'How many of problems has he solved?'

b Combien a-t-il résolu [ _ de problèmes]? 'How many has he solved of problems?'

As illustrated in (6), the wh-element combien can either pied pipe the whole DP as in (6)a or move alone leaving the lexical restriction in situ, as in (6)b. However in the weak island environment in (5), only the pied piped version yields a well formed result. Why should the presence vs absence of a lexical restriction in the moved phrase make a difference? There is substantial cross-linguistic

\footnotetext{
${ }^{1}$ We will not discuss here the possible role of interpretive properties, such as the "discourse-linked" character of the lexical restriction.
} 
evidence that presence of a lexical restriction in the wh-phrase has a grammatical impact. As an illustration, consider the contrast in (7) in Italian:

\author{
a * Dove Gianni ha messo il libro? \\ 'Where Gianni put the book?' \\ b In che cassetto Gianni ha messo il libro? \\ 'Into which drawer Gianni put the book?'
}

The difference in (7) has been interpreted as due to the fact that the two types of wh-phrases target distinct positions in the left periphery of the clause, such that only the position targeted by the simple wh-element triggers obligatory leftward movement of a verbal constituent (Rizzi (1997, 2006), thus disallowing the subject to break the adjacency with the inflected verb. ${ }^{2}$

Going back to the asymmetries in (4) and (5), the relevance of the presence of a lexical restriction within the wh-phrase undergoing movement can be expressed in terms of the featural approach to RM developed in Starke (2001) and summarized in the schema in (8), where A and B are abstract morphosyntactic features triggering movement:

(8) $\begin{array}{llll}\mathrm{X} & \mathrm{Z} & \mathrm{Y}\end{array}$

I) $\quad+\mathrm{A} \quad \ldots .+\mathrm{A} \quad \ldots<+\mathrm{A}>\quad$ (identity)

II) $+\mathrm{A},+\mathrm{B} \ldots .+\mathrm{A} \ldots<+\mathrm{A},+\mathrm{B}>\quad \mathrm{OK} \quad$ (inclusion)

III) $+\mathrm{A} \quad \ldots .+\mathrm{B} \quad \ldots<+\mathrm{A}>\quad \mathrm{OK} \quad$ (disjunction)

If we look at the set-theoretic relations holding between the feature specification of the target $\mathrm{X}$ and the intervener $\mathrm{Z}$, three main cases arise: identity, inclusion and disjunction. When the intervener's specification is identical to the target specification (8I) as in the examples (3)b, (5)b, the structure is ruled out by RM. When the featural specification is disjoint (8III) as in, e.g., wh- movement across a subject (as in (3)a), the principle is satisfied and the structure is well formed. Under Starke's approach the principle is stated in such a way that it also rules in case 8II, in which the featural specification of the intervener is properly included in the featural specification of the target. Therefore examples like (4) and (5)a are ruled in under this approach. The inclusion configuration is illustrated in (9) for example (4), with the target specified as both $+Q$ (the feature designating interrogative operators) and +NP (the feature designating nominal expressions with a lexical restriction):

\footnotetext{
${ }^{2}$ A particularly striking piece of evidence for a positional difference is offered by certain North Eastern Italian dialects, which exhibit patterns like the following, discussed in Munaro (1999), in which the lexically restricted wh-phrase and the simple wh-phrase end up in clause initial and clause final position, respectively:

i. a Con che tosat à-tu parlà?

'With which boy did you speak?'

b Avé-o parlà de chi?

'Have you spoken of whom?'

According to Munaro cit., both wh-phrases move to the left periphery, but the bare wh-phrase targets a lower position, and the derivation then involves further remnant movement of the rest of the clause to a higher topic-like position, while the lexically restricted wh-phrase targets an even higher position in the CP. See also Poletto \& Pollock (2009).
} 
(9) The Inclusion configuration :

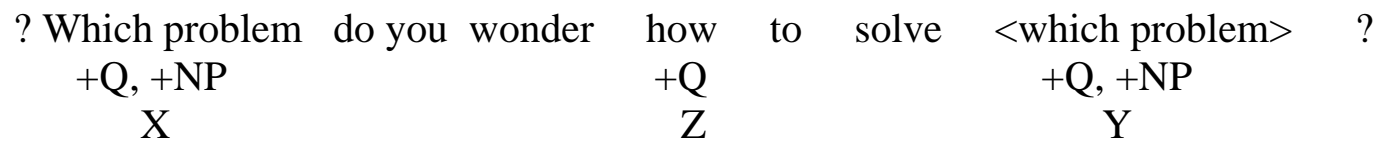

\section{Object relatives in children}

This approach permits a natural characterization of the difficulty that children experience with object relatives (and other A' constructions on the object). ${ }^{3}$ In Friedmann, Belletti \& Rizzi (2009) it is assumed that in the early systems a stricter version of the principle applies than in adult grammars, to the effect that also the inclusion configuration of (8) is ruled out: in this more restrictive system, even the identity of a single constitutive feature shared by the target and the intervener suffices to disrupt the relation. Thus in (1) it is the lexically restricted ([+NP]) character of both the relative head and the intervening subject which disrupts the chain connection between the relative head and the object gap for the child. This is illustrated in (10) for example (1); +R stands for the scope-discourse (or "criterial") feature attracting the relative head, and +NP characterizes its lexically restricted nature as is the case in headed relative clauses:

(10) Headed object relative crossing over a lexically restricted subject:

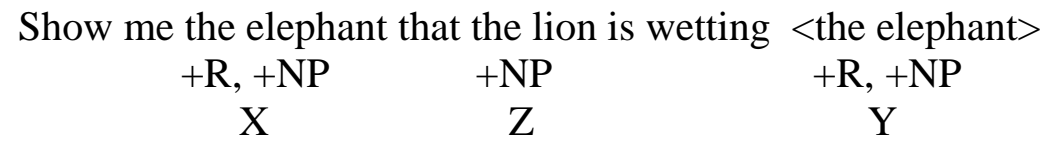

In the series of experiments reported in Friedmann, Belletti, Rizzi (2009), 22 children speaking Modern Hebrew aged 3;7-5;0 (M=4;6, SD = 0;5) were tested on the comprehension of different kinds of A' constructions in Hebrew . Expectedly, they comprehended well Subject relatives in which no intervention arises, but had severe problems in the comprehension of Object relatives ( $90 \%$ SRs, 55\% ORs).

In order to test the validity of the hypothesis that RM is involved in the problematic comprehension of (10), we manipulated the lexical restriction feature either on the relative head or on the intervening subject, thus turning the inclusion configuration of (10) into a disjunction configuration. The prediction was that the comprehension should significantly improve in both cases. A construction illustrating the first type of manipulation is a free relative in which a lexically unrestricted wh-pronoun crosses over a subject as in (11):

(11) Free object relative:

$\begin{array}{ccc}\text { Show me who the lion is wetting } & <\text { who }> \\ +\mathrm{R} & +\mathrm{NP} & +\mathrm{R}\end{array}$

The second manipulation is a structure were the lexically restricted relative head crosses over a lexically unrestricted subject pronoun as in (12):

\footnotetext{
${ }^{3}$ The question whether the difficulty with object relatives is general or is restricted to languages with head initial relative constructions is controversial. See Laka (this volume) for a discussion on Basque which highlights the possible relevance of ergativity over and above the headedness of the language.
} 
(12) Headed object relative crossing over an intervening pronominal subject:

Show me the elephant that they are wetting $\begin{gathered}<\text { the elephant }> \\ +\mathrm{NP},+\mathrm{R}\end{gathered}$
+ Pron

Here we have reported the English equivalent of the Hebrew constructions that were tested. The prediction of the RM approach was borne out in both cases. In the free relative case of the type in (11) the comprehension of the object relative raised from $55 \%$ to $79 \%$, getting close to the subject free relative value (84\%). In the case of the crossing of a pronominal subject comprehension of the headed object relative also raised up to 83\% (Friedmann, Belletti, Rizzi (2009) experiments, 1, 3 and 4 for details).

Summarizing, these results showed that comprehension significantly improved in children if the target and the intervener were made structurally dissimilar, in fact featurally disjoined, with only one of them being lexically restricted.

As for adults, the selective violability of weak islands as in (9) shows that their grammar tolerates situations of featural inclusion. Hence, the crucial case of headed object relatives crossing over a lexically restricted subject is expected to be unproblematic. Under this approach, the same formal principle, RM, applies in a slightly stricter form in children than in adults. In the reference quoted, we speculated that the reluctance of children to admit configurations of proper inclusion relates to the difficulty of computing such configuration involving comparisons between feature sets. The child's system thus rules in only the simpler case of disjunction. ${ }^{4}$ This approach develops the same line of analysis as Grillo 2008's approach to the difficulties that agrammatic speakers experience with different $A^{\prime}$ constructions on the object, a difficulty which is also related to RM, applying in systems with reduced computational resources.

\section{Passive and intervention.}

Another well known instance of a structure which successfully overcomes a potential intervention configuration in adult grammars is passive. If the external argument in a passive structure is syntactically projected (as would follow from Baker's 1988 Uniformity of Theta Assignment Hypothesis, a hypothesis also supported by the fact that the external argument is a syntactically active implicit argument), then, movement of the object to the clausal EPP position would seem to cross over the position of the intervening external argument, a straight violation of RM. Collins 2005 has proposed that intervention here is voided by a preliminary leftward movement of a VP chunk containing the verb and the object and excluding the external argument, the operation he refers to as smuggling. The object can then move from the derived position of the VP chunk, without violating RM as illustrated in (13); to enhance clarity, the moved (smuggling the object DP in Collins's terms) VP chunk is highlighted in grey in (13) :

(13) $\left[_{\mathrm{TP}}\right.$

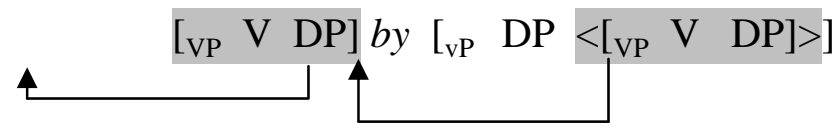

The acquisition of passive is also delayed in acquisition ( a well known developmental finding; e.g. Borer \& Wexler 1987, and much subsequent work). Under Collins' analysis, it is natural to

\footnotetext{
${ }^{4}$ See Belletti, Friedmann, Brunato, Rizzi (2010/submitted) for the discussion of the remaining set theoretic relation, intersection, in children and adults in the context of the discussion of the possible status of the gender feature. The greater complexity of object relatives manifests itself also with adults in a variety of experimental conditions in psycholinguistics: see Warren \& Gibson 2006 and much experimental work discussed there.
} 
conjecture that the complexity of passive structures may be due to the operation moving the VP chunk (smuggling ) that they involve (see Hyams \& Snyder (2007) for a similar proposal).

If an analysis à la Collins is adopted, the way intervention is avoided in passive structures is different from what we have seen in object relatives: in passive, intervention is simply eliminated through the additional movement operation of the VP chunk. This opens up the interesting possibility that object relatives and passive develop independently. We may then expect that the cost in terms of complexity in child grammar will not be equal, one being favoured over the other. That this may be so is shown by striking recent experimental results of elicited production of object relative clauses in Italian (an adaptation of Novogrodsky and Friedmann (2006) design). At the age when passive starts being acquired by children (after around age 5 in Italian), one clearly preferred strategy to cope with the production of the complex object relative structure is to transform it into a subject relative through passive (Belletti 2009, Utzeri 2007, Belletti \& Contemori 2010 and references cited there).

As an illustration, consider the pair in (14); instead of the object relative that was targeted in the elicitation experiment, children often opted for the production of a subject relative with passive:

(14) Elicited Object Relative: Vorrei essere il bambino che la mamma copre

I would rather be the child that the mother covers

Produced (Subject) Relative: Vorrei essere il bambino che è coperto dalla mamma

I would rather be the childe that is covered by the mother

The passive choice follows a clear developmental path, with older children adopting it to a larger extent (up to 59\% in children aged 6-11; from $8 \%$ at age 5, to $22 \%$ at age 6 in younger children. Children had no problems in producing subject relatives, also elicited in the experiment, from the youngest group on : e.g. 89\% at age 4; see Belletti (2009) and Belletti \& Contemori (2010) for detailed discussion.). ${ }^{5}$ In the same elicitation experiment, two groups of Italian adults have been tested: the results were particularly striking as the two groups produced up to $93 \%$ and $87 \%$ of relatives with passive, respectively, when an object relative of the type in (14) was the target of elicitation (Elicited Subject relatives were produced at ceiling, e.g 99,5\% in the second group). Clearly, use of passive yielding the production of a subject relative in place of an objet relative, with no change in the distribution of the theta roles associated to the different arguments, is a favoured option under the experimental conditions set in the elicitation design; and children tend to approach the adult performance as they grow older. ${ }^{6}$ From the perspective of the question raised above, it can be concluded from these results that, not only object relatives and passive develop independently, but also that the computation involved in passive is favoured over the one involved in the direct derivation of an object relative. So, through passive, the (headed) object relative is realized as a subject relative, preserving the intended meaning and the interpretation of the arguments. And passive is adopted in the same relative environment, as soon as development allows it. $^{7}$

Why should passive be favoured over the direct computation of an object relative? It is natural to think that the relevant crucial notion is intervention: the derivation where intervention is totally

\footnotetext{
${ }^{5}$ Data on older children, currently under collection in ongoing work by C. Contemori and A.Belletti, confirm this path.

${ }^{6}$ Similar results have also been found in various other languages for children at age 5 (Friedmann et al (in prep) report results from several languages investigated through the same elicitation method under the frame of the Cost Action/33, Crosslinguistically Robust Stages of Children's Linguistic Performance).

${ }^{7}$ Younger children up to age 5 tend to produce different structures, often misinterpreting the task, when an object relative is elicited. See the references quoted for detailed discussion.
} 
avoided, as it happens in passive under the analysis implicating movement of the verbal chunk through smuggling is the derivation which is adopted. ${ }^{8}$

Moving verbal chunks through operations ultimately reducible to Collins' smuggling, where portions of the verb phrase are involved, is a fairly widespread computational option; its instantiation in passive is just one of its occurrences. The fact that intervention by the external argument is avoided through this derivational mechanism in the case of passive is just one of its consequences. Hence, there is no special status of smuggling strictly related to passive in this respect.

Another structure where movement of a verbal chunk can be argued to be implicated in a way similar to passive is with psych-verbs of the preoccupare (worry) class illustrated in (15) (Belletti \& Rizzi (2009) for further details; Belletti \& Rizzi (1988) for the original analysis of psych verbs on which the new account is based):

(15) a Questo problema preoccupa Gianni This problem worries G.

b $\quad \ldots . . \quad\left[\ldots .\left[{ }_{\mathrm{vP}} \ldots \mathrm{v}[\mathrm{vp}\right.\right.$ Experiencer $\mathrm{v}$ [vp preoccupa Theme $\left.]\right]$

In (15)b the verbal chunk containing the verb and the theme internal argument is moved to some higher position within a complex vP shell, crossing over the higher experiencer argument; extraction of the theme to the clausal EPP position to yield the structure in (15)a can occur from this derived position. Again, intervention is avoided in exactly the same fashion as in passive in this derivation. The only difference is that the movement of the verbal chunk is triggered here by some lexical property of the verb of this class, not by some morphosyntactic property, as is the case in passive. ${ }^{9}$ Similar manipulations of the clausal structure involving different portions of the verb phrase, triggered by different properties - lexical, morphosyntactic, informational - have been proposed in the literature, e.g. in Cinque (1999) the movement of the portion of functional structure immediately including the verb phrase produces an apparent reordering of the adverbial hierarchy; in Belletti (2004) the movement of a portion of the verb phrase containing the verb and object and excluding the external argument yields a vP peripheral clause internal topicalization of the verbobject sequence with the subject remaining postverbal; and in ongoing work by D. Sportiche,, I. Roberts, Romance causatives are analyzed along lines which capture the fundamental insight of classical analyses making reference to VP-preposing (Burzio 1986, Rouveret \& Vergnaud 1980). This very sketchy list is simply meant to indicate that the process which moves a verbal chunk in passive, with the effect of remodulating intervention from the external argument with respect to the internal argument, is not an isolated process. From an acquisition perspective the process seems to need some time to develop, as is shown by the delay of passive in the first years of syntactic development; but once it develops, children and adults appear to resort to it quite extensively. Avoiding intervention through smuggling thus is a widespread option across the board for adults and older children .

\footnotetext{
${ }^{8}$ Of course, this holds all other things being equal, including the general appropriateness of the derived sentence, also from the point of view of its informational value, an aspect that we do not discuss here for reasons of space. See also Gehrke \& Grillo (2009) on a semantic motivation for movement of a verbal chunk in passive, tied to the event structure of the verb phrase.

${ }^{9}$ In Belletti \& Rizzi (2009), we speculate that some "cause” type verbal head (or some close equivalent in systems of lexical decomposition as in ,e.g., Ramchand (2008)) could be the trigger of the verbal chunk movement in this case, thus incorporating Pesetsky's (1995) observations on the special interpretive status of the theme in his comments to our original 1988 analysis. See the reference quoted for more detailed discussion.
} 


\section{Speculations on subject control and intervention}

Going back to control, we may now try to explain the delay of subject control with promise type verbs through the same theoretical ingredients. Consider the following possible approach to control: PRO and its controller must be connected by a search operation (Agree-like, as in Chomsky 2000) constrained by RM. Control is therefore local and obeys the Minimal Distance Principle now subsumed under RM (a result that can thus be achieved without necessarily adopting a movement approach to control: see Hornstein 1999, Landau 2003 for discussion).

If this is so, subject control across an intervening object should be barred in principle:

\section{(16) Bill promised John [ PRO to leave early ]}

This straightforwardly accounts for the fact that children systematically misinterpret such sentences as cases of object control, Carol Chomsky's result. But why is subject control possible at all in adult grammar? We have considered two possible techniques that avoid intervention in different types of local relations:

1. The intervention configuration holds, but the featural specification of the intervener is properly included in the featural specification of the target (this is the case of object relatives in adult grammars).

2. The intervention configuration is destroyed by a movement of a verbal chunk ("smuggling”), which bypasses the intervener.

So, a natural possibility to explore is that subject control across an object in the adult grammar may involve one of these avoidance techniques. A recourse to technique 1. does not look very plausible: subject and object in (16) don't look amenable to a natural featural differentiation making the object's specification a proper subset of the subject's specification and making the case different from a well formed object control:

\section{Bill ordered John [ PRO to leave early ]}

So, we are left with hypothesis 2.: subject control verbs undergo a smuggling-type process which makes the subject the closest controller for PRO. In this sense, subject control across an object would be akin to raising across an experiencer (John seems to Mary to be a nice guy), which, according to Collins (2005) also involves a smuggling operation voiding the intervention of the experiencer (again, under the approach to control we have outlined this analogy between control and raising would not imply a raising analysis of control). Smuggling operations are costly (even though they may be less costly than the other avoidance technique of computing inclusion relations, as we have argued in section 4), and are acquired only in a relatively late temporal window, as the case of passive shows: this would give us a key to understand the delay of subject control in acquisition.

But why would a smuggling-like operation apply with promise type verbs, and not with order type verbs? Another quote from Carol Chomsky's seminal book is helpful here:

"Promise is in a distinct syntactic category from these command verbs [order, force, compel, require, ...]. We may say that each semantic class (command verbs on the one hand and promise on the other) has associated with it a separate syntactic process” (C. Chomsky 1969, p. 12) 
We would like to try to follow Carol's hint that the syntax - lexical semantics interface plays a critical role here by sketching out an analysis in terms of lexical decomposition of the verb structured meaning à la Hale \& Keyser (1993) and much subsequent more recent work in a similar vein on the lexical and syntactic properties of verbs (in particular, Folli \& Harley (2007), Ramchand (2008); Travis (2000)). Promise and order allow paraphrases with different light verbs plus nominal elements:

(18) John made Bill the promise to leave early

(19) John gave Bill the order to leave early

Following this type of approach, we will assume that lexical verbs such as promise and order are obtained through incorporation of the lexical object noun into the relevant light verb. If give in (19) is further decomposed as make-have, we have the following representation (in which $\mathrm{v}_{\mathrm{x}}$ is a light verb with "interpretive flavour" $\mathrm{x}$ ):

\section{(20) John $v_{\text {make }}$ [ Bill $v_{\text {have }}$ [ order [PRO to go ]]]}

Here order incorporates first into light verb $\mathrm{v}_{\text {have }}$ and then into $\mathrm{v}_{\text {make }}$; the object Bill is the closest potential controller for PRO in the derived representation, hence we have object control in this case. Consider now promise. If (18) is an accurate paraphrase close enough to the abstract syntactic representation, and $v_{\text {make }}$ does not further decompose, we do not have a verbal small clause comparable to (20). How is the object integrated into the structure then? We may think that Bill in (18) is a kind of benefactive of the promise. If the benefactive relation is mediated by a benefactive (Ben) particle-like functional head, we would have the following representation:

\section{(21)a John $\mathrm{v}_{\text {make }}$ [ Bill ben [ promise [PRO to go ]]]}

Here the noun promise should incorporate into the light verb $\mathrm{v}_{\text {make }}$ to create the verb promise. But in (21) the two elements aren't local enough for incorporation to take place because of the intervening head Ben. The problem can be overcome by a leftward movement of the chunk [ promise [PRO to go ]], which "smuggles" promise to a position suitable for incorporation:

\section{(22) John $\mathrm{v}_{\text {make }}$ [promise [PRO to go]] [ Bill ben $\mathrm{t}$ ]}

At this point the noun promise can incorporate into the light verb; the surface word order is obtained through extraposition of the infinitive:

(23) John promise $+\mathrm{v}_{\text {make }}\left[\left[\mathrm{t}_{\text {promise }} \mathrm{t}_{\text {infinitive }}\right][\right.$ Bill ben $\left.\mathrm{t}]\right][\text { PRO to go }]^{10}$

\footnotetext{
${ }^{10}$ We suggest that extraposition is made compulsory here by the necessity of having Bill adjacent to the Case assigning/checking v. One might observe that extraposition of the infinitival clause to a high structural position in the clause not c-commanded by the object, would be sufficient to the void intervention configuration; no appeal to movement of the verbal chunk would be needed under this view. However, there would be no principled reason to force obligatory extraposition exactly with these verbs; the option would be stated in an ad hoc way specific to this particular lexical choice and construction. In contrast, the approach we have elaborated in the text suggests principled reasons as to why both movement of a verbal chunk and extraposition should occur with subject control verbs. We have expressed extraposition in traditional rightward terms, but an antisymmetric analysis with double movement to the left (Kayne 1994) would also yield the required configuration
} 
On this representation the object Bill does not c-command PRO, hence it does not structurally intervene between the subject and PRO. Subject control thus obtains, as the subject is the closest potential controller. A crucial step for producing the relevant configuration for subject control across the benefactive object is the "smuggling" operation extracting the phrase [promise [PRO to go]] from the c-domain of the object. The delay of subject control can thus be looked at as a particular case of the delay that children experience with smuggling operations.

Subject control involves, in this analysis, at least as much derivational machinery as passive, and in fact more: the obligatory extraposition of the infinitive, arguably motivated by Case theoretic considerations (see fn 8) makes the derivational computation of subject control, under our analysis, more complex than passive. ${ }^{11}$ It may thus be expected that subject control develops even later than passive, and with the individual variation that Carol Chomsky discovered.

\section{References}

Baker, M. (1988) Incorporation, Chicago University Press

Belletti, A. (2009) “Notes on Passive Object Relatives”, in press in P.Svenonius ed., Functional Structure form Top to Toe, Oxford University Press

Belletti, A. \& L. Rizzi (1988) "Psych-verbs and Th-Theory", Natural Language and Linguistic Theory, 6, 291-352

Belletti, A. \& L. Rizzi (2009) “Moving verbal chunks”, in press in Brugè L., A. Cardinaletti, G.Giusti, N.Munaro, C.Poletto, eds., Functional Heads, Oxford University Press.

Belletti, A. \& C.Contemori (2010) "Intervention and attraction. On the production of Subject and Object relatives by Italian (young) children and adults", in press in the Proceedings of GALA 2009, University of Lisbon, September 2009

Belletti, A., N. Friedmann, D. Brunato, L. Rizzi (2010/submitted) “Does gender make a difference? Comparing the effect of gender on children's comprehension of relative clauses in Hebrew and Italian”, ms. ciscl, Univerisity of Siena, Language and Brain Lab, School of Education, Tel Aviv University

Boeckx, C. (2008) Bare Syntax, Oxford University Press, New York

Borer, H. \& K.Wexler (1987) “The Maturation of Syntax”, in T.Roeper \& E.Williams eds., Parameter Setting, Reidel:Dordrecht

Burzio, L. (1986) Italian Syntax. A Government and Binding Approach, Reidel:Dordrecht

Chomsky, C. (1969) The Acquisition of Syntax in Children from 5 to 10, MIT Press: Cambridge Mass.

Chomsky, N. (2000) “Minimalist Inquiries”, R.Martin, D.Michaels, J.Uriagereka eds., Step by Step, MIT Press: Cambridge Mass,

Chomsky, N. (2001) “Derivation by Phase”, in Ken Hale: a life in language, M. Kenstowicz ed., 152. MIT Press, Cambridge, Mass.

Chomsky, N. (2008) “On phases”, in Foundational Issues in Linguistic Theory: Essays in Honor of Jean-Roger Vergnaud, ed. by R. Freidin, C. P. Otero, and M. L. Zubizarreta, 133-166, MIT Press. Cambridge, Mass.

Cinque, G. (1999) Adverbs and Functional Heads. A Cross-linguistic Perspective, Oxford University Press, New York

Collins, C. (2005) “A Smuggling Approach to the Passive in English”, Syntax, 8.2, 81-120

\footnotetext{
11 The derivational complexity of subject control would be akin to the derivational complexity of raising across an overt experiencer, which also involves both smuggling and extraposition under Collins' analysis. Hirtch and Wexler (2007) have in fact provided experimental evidence that comprehension of raising across an experiencer is substantially delayed in acquisition. We would expect its developmental course to be roughly on a par with the development of subject control
} 
Folli, R. \& H. Harley (2007) "Causation, obligation and argument structure: On the nature of little v”, Linguistic Inquiry 38.2: 97-238.

Friedmann, N., A. Belletti, L. Rizzi (2009) "Relativized relatives. Types of intervention in the acquisition of A-bar dependencies”, Lingua, 119, 67-88

Friedmann. N. et al. (in prep.) “ Children's production of relative clauses”, final paper of WG-3 of the European Cost Action/33

Gehrke, B. \& N.Grillo (2009) How to BECOME Passive, in Explorations of Phase Theory: Features, Arguments, and Interpretation at the Interfaces, K. K. Grohmann ed., Interface Explorations, 231-268, de Gruyter, Berlin \& New York

Hale, K. \& S.J. Keyser (1993) "On argument structure and the lexical expression of grammatical relations”, in The view from Building 20. Essays in honor of Sylvain Bromberger, K. Hale and S. J. Keyser eds., 53-110, MIT Press, Cambridge, Mass.

Hale, K. \& S.J. Keyser (2002) Prolegomenon to a Theory of Argument Structure, MIT Press, Cambridge, Mass

Grillo, N. (2008) Generalized Minimality, LOT, Utrecht, The Netherlands

Hirtch, \& K. Wexler (2007) "The late acquisition of raising: What children seem to think about seem”, in S. Dubinsky and B. Davies (eds.) New horizons in the analysis of control and raising. New York, NY: Springer.

Hornstein, N. (1999) “Movement and Control”, Linguistic Inquiry, 30, 69-96

Kayne, R. (1994) The Antisymmetry of Syntax, MIT Press: Cambridge Mass.

Laka, I. (this volume) “Complexity at the interface of processing and grammar: Subject preferences and asymmetries”

Landau, I. (2003) Movement Out of Control. Linguistic Inquiry 34, 471-498.

Munaro, N. (1999) Sintagmi interrogativi nei dialetti italiani settrentrionali, Unipress, Padova

Novogrodsky, R. \& N. Friedmann (2006) "The production of relative clauses in syntactic SLI: A window to the nature of the impairment”, Advances in Speech-Language pathology, 8, 364375

Pesetzky, David. 1995. Zero Syntax: Experiencer and Cascade, MIT Press

PolettoC., \& J-Y. Pollock (2009) "Another look at wh-questions in Romance: the case of medrisiotto and its consequences for the analysis of French wh-in-situ and embedded interrogatives”, in L.Wentzel, Romance Languages and Linguistic Theory 2006: Selected papers from 'Going Romance', Amsterdam, 7-9 December 2006, vol. 1, 199-258

Ramchand, G. (2008) Verb Meaning and the Lexicon. A First Phase Syntax Cambridge, CUP

Rizzi, L. (1990) Relativized Minimality. MIT Press: Cambridge. Mass.

Rizzi, L. (1997) "The Fine Structure of the Left Periphery" in L. Haegeman ed. Elements of Grammar, Kluwer, Dordrecht, 281-387

Rizzi, L. (2004) "Locality and the left periphery.”, in A. Belletti ed., Structures and Beyond: The cartography of syntactic structures, Vol. 3., Oxford University Press, New York 223-251.

Rizzi, L. (2006) "Selective Residual V-2 in Italian Interrogatives”, in P. Brandt and E. Fuss eds., Form, Structure and Grammar , Akademie Verlag, Berlin, 229-242

Rosenbaum, P.S (1967) The grammar of English predicate constructions, MIT Press, Cambridge Mass.

Rouveret, A. \& J.R.Vergnaud (1980) "Specifying reference to the subject”, Linguistic Inquiry 11, 97-202

Starke, M.(2001) Move dissolves into Merge , PhD dissertation, University of Geneva

Travis, L. (2000) "Event Structure in Syntax", in Events as Grammatical Objects: the converging perspectives of lexical semantics and syntax, C. Tenny and J. Putejovsky eds., CSLI Publications, Standford, Ca.

Utzeri, I (2007) “The production and acquisition of subject and object relative clauses in Italian”, Nanzan Linguistics Special Issue 3, 283-314 